\title{
Assessing AquaCrop model to simulate soil water contents under semi arid climate of Central Tunisia
}

\section{Hiba Ghazouani ${ }^{1, *}$, Basma Latrech ${ }^{1}$, Mguidich Belhaj Amel ${ }^{2}$, Cherni Amani $^{3}$, Boutheina M'hamdi Douh ${ }^{1}$, Ghazouani Issam $^{3}$ and Abdelhamid Boujelben ${ }^{1}$}

\author{
${ }^{1}$ Department of Rural Engineering. Higher Institute of Agronomy. Chott_Mariem \\ Sousse (ISA-CM). Université de Sousse. 4042 Tunisia. *Email: \\ ghazouani_hibaunipaisa@yahoo.com. \\ ${ }^{2}$ Regional Field Crops Research Center (CRRGC). Béja. Tunisia. \\ ${ }^{3}$ Higher School of Agriculture of Kef. University of Jendouba. Kef. Tunisia.
}

\begin{abstract}
The objective of the present study was to preliminary calibrate and validate AquaCrop model based on crop conservative parameters from the literature for plant growth and water stress thresholds. In addition, physical soil characteristics, root growth, duration of plant stages and atmospheric demands were introduced according to field measurements. Based on this preliminary calibration, simulated water contents were compared to a measured data set of water contents retrieved from deficit and full irrigation treatments on a potato cropped field during an experimental year of 2015 . Statistical indexes were computed and finally this performance in simulating water contents were validated under independent measurements carried out during an experiments campaign on the same field on 2014. Moreover, the paper presents the experimental protocol followed for soil characterization, considered as a milestone component for this soil water contents prediction. Results showed, that under the followed preliminary calibration, the model was able to simulate water contents $(\theta v)$. In general, values of Root Mean Square Error were lower than $0.03 \mathrm{~cm}^{3} . \mathrm{cm}^{-3}$ representing the magnitude of error of the time domain reflectometry probe. Moreover values of Nash coffecients were close to 1 confirming the goodness of fit between measured and estimated water contents. Once assessed, the model could be used to study effects of different irrigation strategies on dynamic of water contents aiming to increase water use efficiency.
\end{abstract}

Keywords: Full irrigation; Deficit irrigation; Calibration; Water contents; Validation.
Received

February 22, 2019

Accepted

March 23, 2019

Released

April 30, 2019

Full Text Article

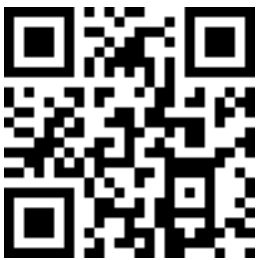

ORCID

(ㄷ) 0000-0002-4601-1528 Hiba Ghazouani

(ㄷ) 0000-0002-5790-0558 Basma Latrech

(1) 0000-0002-1223-5312 Mguidich Belhaj Amel

(D) 0000-0002-0729-588X Cherni Amani

(1) 0000-0002-3439-2212 Boutheina M'hamdi Douh

() 0000-0002-7797-2671

Ghazouani Issam

(1) 0000-0002-3026-9014 Abdelhamid Boujelben 


\section{Introduction}

The scarcity of water resources requires adoption of new strategies and field management aiming to improve water use efficiency (Shahnazari et al., 2007). Agriculture is the most water consumer with about $83 \%$ of the total available water resources. Projections on the near future predict an increasing demand of non agricultural sectors, which will be deeply amplified by climate-land use changes and population growth (Jury and Vaux, 2005). For increasing water use efficiency, it is important to choose a high and well designed irrigation system and to determine the appropriate time and doses to apply irrigation. However, when scheduling irrigation, it is crucial to determine in real time the water status in soil plant atmosphere system or in one of his components. Soil water status is involved in many plant physiological processes (germination, plant growth and nutrition). Moreover, soil water contents effects dynamic water infiltration from the top soil surface, deep drainage, as well as soil evaporation and root extraction. In the last decades, several experimental methods have been implemented at farm and watershed scales to determine the SWC, and a large body of knowledge in terms of tools is now available.

Despite the accuracy of most of the new tools, applicability remains quite expensive and demanding in terms of skilled researchers, especially for a developing country like Tunisia. Methods for soil water content measurements are classified in two main groups: Direct and indirect methods. In the first method, water content is directly measured based on its weight as a fraction of the total weight of the soil. Despite its simplicity, this method is usually destructive since it requires removing soil sample from the field to analyze in the laboratory. In addition, it is a time consuming methods. However, irrigation scheduling needs, usually several measurement of soil water contents at different time of the growth cycle and in several positions of the field.

Because of the above mentioned limitations, direct method is considered not suitable to determine irrigation timing and volumes. Since, a variety of indirect methods have been implemented. Indirect method allows firstly measuring soil water contents via other variables, that are affected by the amount of water on the soil and thereafter associates the variable change to a soil water content change, using physically or empirical calibration relationships (Dane and Topp, 2002). For instance, the dielectric sensors allows measuring soil water contents via dielectrical properties; thermal properties of the soil are monitored in a case of heat flux sensors; Loss of neutrons energy as a result of the collision with other atoms is considered for neutrons scattering techniques (Dane and Hopmans, 2002).

The main advantages of this method are related to the possibility of continuous time and spatial acquisitions through automation and datalogger and to be even repeated in the same spot. Moreover, it is non-destructive and does not need a long time for data elaboration. However, for a low income country like Tunisia, farmers and research centers do not usually have access to such advanced tools. Since, agrohydrological models, especially, when are available could be considered as a powerful tool to predict the dynamic of water on the soil profile (Rallo et al., 2012). In fact, agrohydrological models provide a conceptual description of the water cycle on soil plant atmosphere system. All these models involves empirical or physically approaches relating a certain inputs like precipitation and irrigation to the model outputs like soil water content, transpiration or yield. The first category of these models are considered as blackbox systems using regression techniques 
or transfer functions to evaluate the model output, whereas the seconds uses more complicated sub models to represent each single process.

Simplified agrohydrological water balance models using a black-box approach include, for example, FAO-56 model (Allen et al., 1998) or AquaCrop (Steduto et al., 2009), whereas physically based models includes, between others, Hydrus-2D/3D (Šimůnek and Van Genuchten, 2008) and SWAP (Van Dam et al., 2008). Amongst simplified models, AquaCrop Model assumes the soil as a water reservoir of a given maximum capacity, defined as total available water, TAW, that can be evaluated once known soil field capacity, permanent wilting point and after defining the rooting depth. Recently, several researchers have found satisfactory results with AquaCrop when simulating plant growth and production for many crops like sunflower, beans, winter wheat and tomato (Steduto et al., 2009).

Furthermore, Farahani et al. (2009) suggested that AquaCrop is a simple model joining robustness to accuracy. Moreover, the model does not need numerous input parameters, especially with the existence of conservative parameters of Hsiao et al. (2009). Since, model calibration does not require skilled researchers. Conservative parameters are not influenced by geographical site nor crop cultivar (Steduto et al., 2009). Heng et al. (2009) and Hsiao et al. (2009) suggested that AquaCrop is able to simulate crop development and productions under non stressed conditions. However, results from other studies underlined the fact that the performance of the model is lower under stress conditions (Katerji et al., 2013). This low performance could be attributed to different factors among which unsatisfactory prediction of soil water content prediction, being on itself affected by root extractions, atmospheric demand and stress functions.

The objectives of this study were two (i) calibrate and validate the model based on crop conservative parameters from the literature for plant growth and water stress function and measurements of physical soil characteristics, root growth, atmospheric demands and calibrated (ii) to use the calibrated model for predicting soil water contents under deficit and full irrigation treatments on a cropped field.

\section{Material and methods}

\section{treatment}

\section{Field experiment and irrigation}

An experimental field was carried out at the High Agronomic Institute of Chott Mariem, Sousse, Tunisia (longitude $10.5632^{\circ} \mathrm{W}$; latitude $35.9191^{\circ} \mathrm{N}$, altitude $19 \mathrm{~m}$ a.s.l.) on a split plot design. A general agrometeorological characterization of the surrounding region was carried using 15 years of meteorological data, from 2000 to 2015, recorded at the climate station of Chott Mariem, belonging to National Institute of Meteorology (INM) network.

Figure 1 shows the ombrothermic diagram of Bagnouls and Gaussen (1953), allowing identifying the "dry period" during which monthly average precipitation (P), expressed in $\mathrm{mm}$, is not greater than twice the monthly average temperature (T) expressed in degree Celsius $(\mathrm{P}<2 \mathrm{~T})$. The dry period is identified by tracing, from the intersection points of the two curves, the perpendicular to the time axis. As can be observed from Figure 1, precipitation is concentrated in autumn and winter periods (mainly in December and January) and that the dry period in the examined region lasts about six months, from mid of March to the last decade of September. 


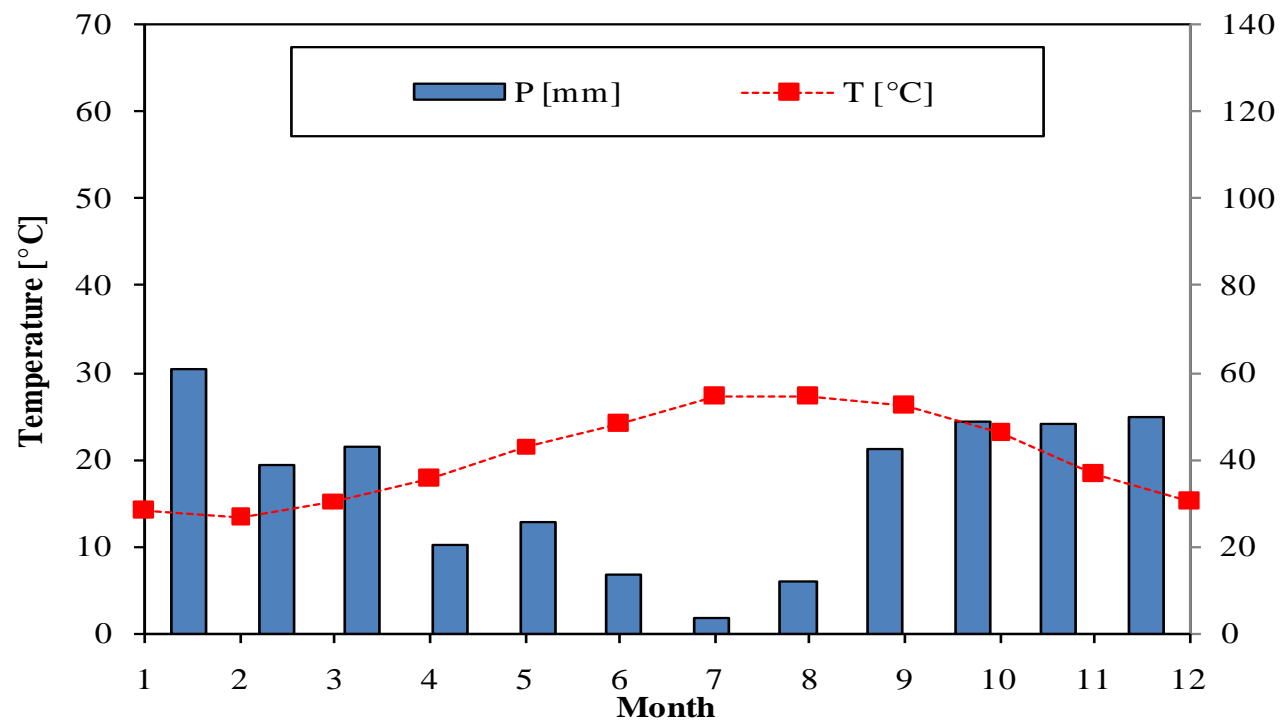

Figure 1. Ombrothermic diagram of Bagnouls and Gaussen.

In 2014 and 2015, tuber seeds of the same potatoes cultivar (Solanum tuberosum L., cv. Safran), were planted on January, 15th and on January, 22nd, respectively, at distance of $0.40 \mathrm{~m}$ along the row and $0.80 \mathrm{~m}$ between the rows, in an experimental plot, $25 \mathrm{~m}$ length and 7 $\mathrm{m}$ wide. The experimental plot was divided in two subplots (treatments T1, T2) subjected to similar seasonal management, except for irrigation doses (Figure 2). Treatment T1 received irrigation volumes corresponding to the maximum crop evapotranspiration estimated between two consecutive watering, whereas treatments T2 (deficit irrigation) received approximately the half of volumes provided in the treatment. Volumetric counters (precision $0.1 \mathrm{dm}^{3}$ ) were installed into the field to check during each watering the total volume provided in the plots.

A subsurface drip irrigation system characterized by a single 710 distribution pipe per plant row, installed at $0.20 \mathrm{~m}$ depth. Co-extruded drip emitters, spaced $0.40 \mathrm{~m}$, discharged a flow rate of $3.5 \mathrm{~L} / \mathrm{h}$ at nominal pressure of $100 \mathrm{kPa}$. A weather station station located at $300 \mathrm{~m}$ far from the experimental site in 2014 and inside the experimental field in 2015 provided daily records of solar radiation, precipitation, maximum and minimum temperature and relative humidity and wind speed at $2 \mathrm{~m}$ height, w2m. From these records, reference evapotranspiration (ETo) was computed using the Penman-Monteith equation (Allen et al., 1998). Water contents were monitored using a Trime Time domain reflectomerty apparatus (Imko Micromodultechnik, Germany) for both investigated years.

\section{Soil characterization}

The textural curve, providing a quantitative representation of particles soil distribution as a function of their diameter, was determined by sieving and sedimentation. In particular, the distribution of particle sizes larger than $74 \mu \mathrm{m}$ (200 mesh sieve) was determined by sieving, while the distribution of particle sizes smaller than $74 \mu \mathrm{m}$ was evaluated by following a sedimentation process, with the Bouyoucos hydrometer (ASTM 152H). The former analysis is based on screening of the soil fractions, while the latter follows the sedimentation of soil particles by gravity, according to the Law of Stokes. 


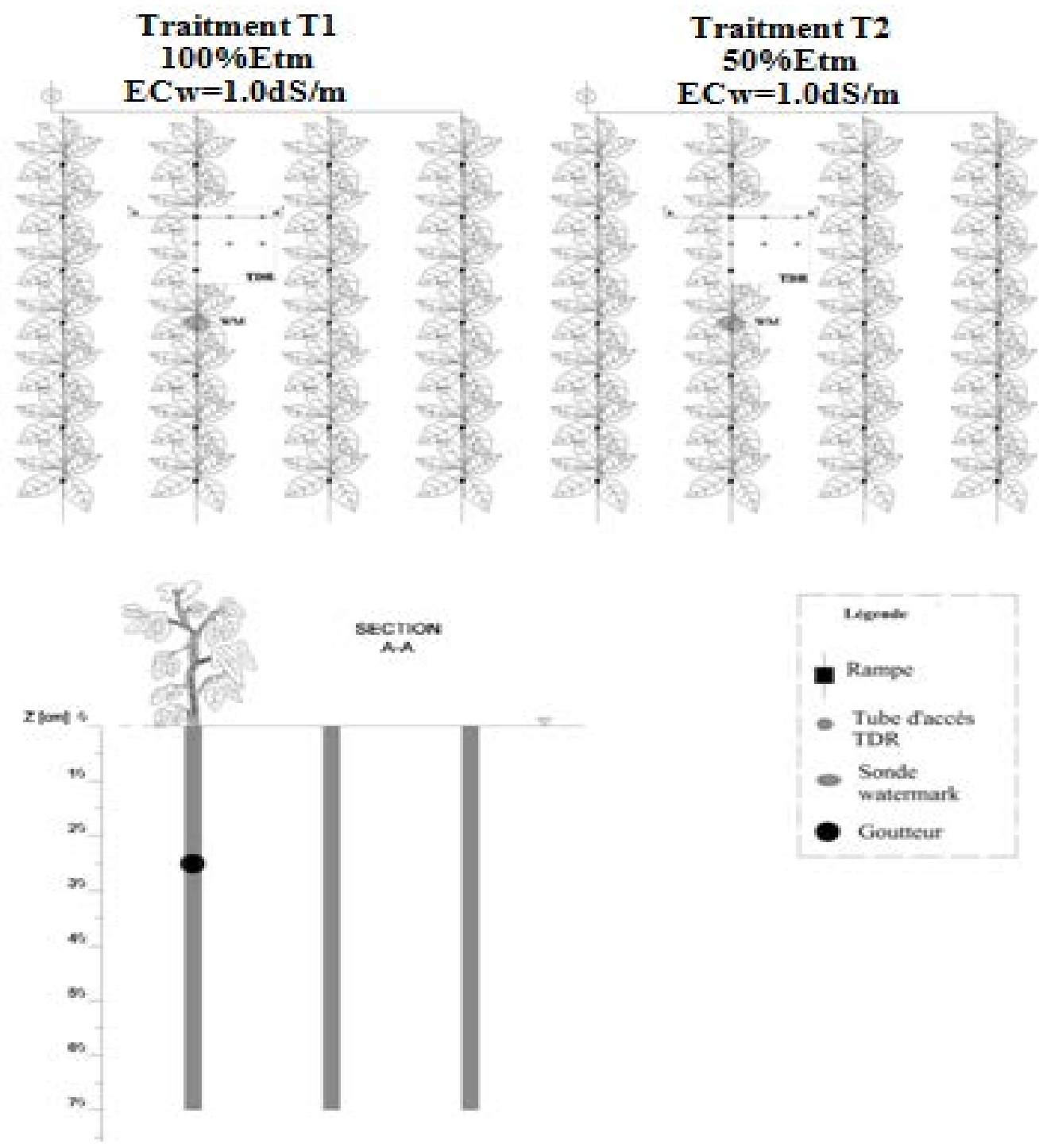

Figure 2. Design of the experimental plot during the experimental seasons of 2014 and 2015.

The use of the ASTM 152H type hydrometer is based on a standard temperature of $20^{\circ} \mathrm{C}$ and a particle density of $2.65 \mathrm{~g} \mathrm{~cm}^{-3}$, with units expressed as grams of soil per liter of water. The experimental protocol is divided in three stages: i) preparation of soil sample, ii) hydrometer calibration and iii) evaluation of falling height of soil particles. Soil samples were initially air dried at room temperature, crushed in a mortar in order to mechanically break the big aggregates by using a rubber hammer and finally sieved at $2 \mathrm{~mm}$. This operation was repeated until the soil particles were distributed in single grains. After preparing the sample, the fraction passing through the $2 \mathrm{~mm}$ riddle was sifted through a series of decreasing diameter sieves $(1.68,0.84,0.59,0.42$, $0.25,0.177,0.149,0.125,0.088$ and 0.074 $\mathrm{mm}$ ), while animating the sieve with continuous lateral and vertical movement, so that the sample was always in movement. The retained and passing fraction through each screen were then weighed to be sure that the sum of fractions retained and passing was equal to the initial weight. The percentage of particles with average diameter smaller than the i-th sieve grid size was determined as: 


$$
F_{i}=\left(\frac{P_{t o t}-P_{i}}{P_{t o t}}\right) * 100
$$

where $P_{i}$ is the weight of soil retained in the $\mathrm{i}$-th sieve fraction and $\mathrm{P}_{\text {tot }}$ is the total sample weight.

The results of the analysis allowed identifying the three fractions constituting the soil sample and specifically clay $(\mathrm{d}<0.002 \mathrm{~mm})$, silt $(0.002<\mathrm{d}<0.05 \mathrm{~mm})$ and sand $(0.05<\mathrm{d}$ $<2.0 \mathrm{~mm}$ ) and finally categorizing the soil according to USDA classification system.

Soil water retention curve represents the relationship between matric potential, $\mathrm{h}$, and soil water content, $\theta$; the knowledge of this relationship is quite important for irrigation management because it allows quantifying the volume of water stored per unit of soil volume at each fixed soil matric potential. For the investigated soil, the water retention curve was determined on soil samples collected at three different depths by means of tensiometric and pressiometric methods (Figure 3a,b). The former, used for matric potentials ranging between $0 \mathrm{hPa}$ (saturation) and about $-150 \mathrm{hPa}$, followed the water column technique performed in Buckner funnels, equipped with porous plates with an air entry point $\mathrm{h}=-200 \mathrm{hPa}$ (Dane and Hopmans, 2002). Undisturbed soil samples collected in the field, $8.0 \mathrm{~cm}$ diameter and $5.0 \mathrm{~cm}$ height, after saturation were placed in hydraulic contact with the bulk water through the porous plate (Figure 3a). A glass burette, hydraulically connected to the funnel and free to move vertically along a measuring rod, allowed to fix the different values of soil matric potential at which to determine the corresponding soil water contents.

Matric potential can be fixed based on the difference of level between the center of the sample and the water meniscus in the burette. Once fixed the position of water meniscus by regulating the burette level, depending on the matric potential in the sample, a volume of water flowed out from the sample in a certain time interval and subsequently water level in the burette rises. After registering the amount of drained volume, the burette level was reduced and the water meniscus placed again at its initial value, so to start with the second step. After a succession of similar steps and once the equilibrium was reached (absence of further drainage), the sum of drained volumes, representing the amount of water lost from the initial to the final soil water potential, was determined. According to the experimental protocol, matric potentials at which soil water content was determined were fixed equal to -5 , $10,-20,-40,-70,-100$ and $-150 \mathrm{hPa}$. Usually, the complete test on each soil sample takes about 30 to 40 days, depending on the soil type. Nevertheless, the time required to reach the equilibrium is variable depending on the potential considered: it ranges from one to two weeks for the first three potentials $(-5,-10,-20 \mathrm{~cm})$ and from 3 to 4 weeks for the final values $(-40,-70,-100,-150$ $\mathrm{cm})$. At the end of the experiment, the sample was weighed and then ovendried to determine the water content corresponding to the last applied potential. Soil water contents at the remaining soil matric potentials were then determined by induction, by summing the amount of water drained from the samples during consecutive steps. For values of soil matric potentials ranging between $-330 \mathrm{~cm}$ and $-15,000$ $\mathrm{hPa}$, the pressiometric method was applied by using the Richard apparatus 
(Dane and Hopmans, 2002) as shown in Figure 2.6b. For each depth of the soil profile, three $5 \mathrm{~cm}$ diameter and $0.5 \mathrm{~cm}$ height plexiglas rings were filled with 50 $\mathrm{g}$ of sieved soil $(0.2 \mathrm{~mm})$ and, after saturation, placed in the pressure plate extractors, in which they were subjected to positive pressure values of $330,1,000$,
3,300 and $15,000 \mathrm{hPa}$. Once the equilibrium was reached at each fixed pressure and the soil did not drain further amounts of water, the samples were weighted and then oven-dried in order to determine the corresponding soil water contents. a)

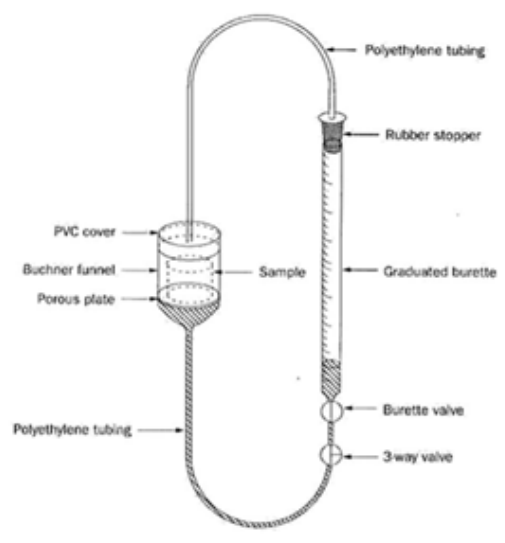

b)

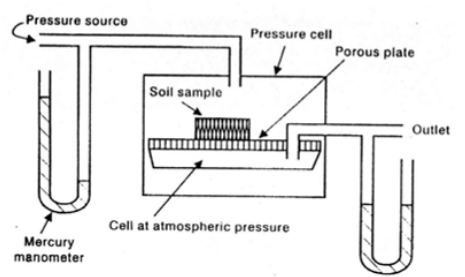

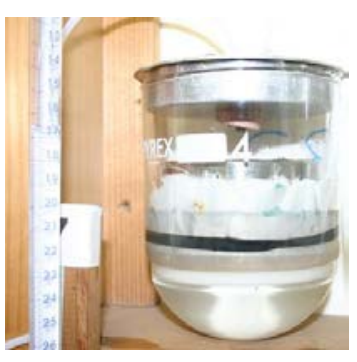

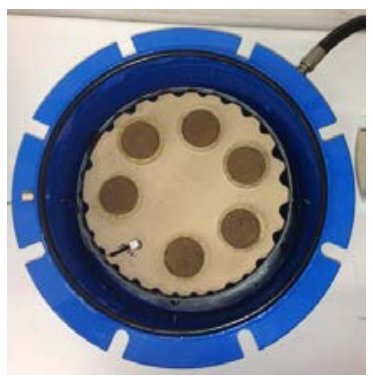

Figure 3. a) Determination of soil water retention curve with tensiometric, and (b) pressiometric methods.

Saturated soil hydraulic conductivity was determined according to the Darcy method on undisturbed soil samples $8.0 \mathrm{~cm}$ diameter and $5.0 \mathrm{~cm}$ height, by using the constant head permeameter represented in Figure 4. The samples were initially gradually saturated from the bottom by capillarity, in order to evacuate all air in the pores and to avoid that bubbles of entrapped air could affect measurements. After saturation, each soil sample was placed in a funnel connected to an outflow collector. Water was applied to the top of the sample at a rate to maintain a shallow water film on the soil surface, by 
using a Mariotte bottle. The steady state water flow was measured by weighting the cumulative drained volumes at constant time intervals. Each experiment was stopped when the steady state condition was reached, that resulted on average after $60 \mathrm{~min}$. In particular, the experiment was considered complete when, after the first $30 \mathrm{~min}$, the difference in weight percentage between two successive readings was less than $0.2 \%$. Saturated soil hydraulic conductivity, $\mathrm{K}_{\mathrm{s}}(\mathrm{cm} / \mathrm{s})$, was finally calculated as:

$$
K_{S}=\frac{\Delta v}{\Delta t A} \frac{L}{(L+H)}
$$

where $\Delta v\left[\mathrm{~cm}^{3}\right]$ is the volume of water drained from the sample in the time interval $\Delta \mathrm{t}$ [s], $\mathrm{L}[\mathrm{cm}]$ and $A\left[\mathrm{~cm}^{2}\right]$ are the height and the cross-sectional area of the soil sample and $\mathrm{H}$ $[\mathrm{cm}]$ is the hydraulic head.
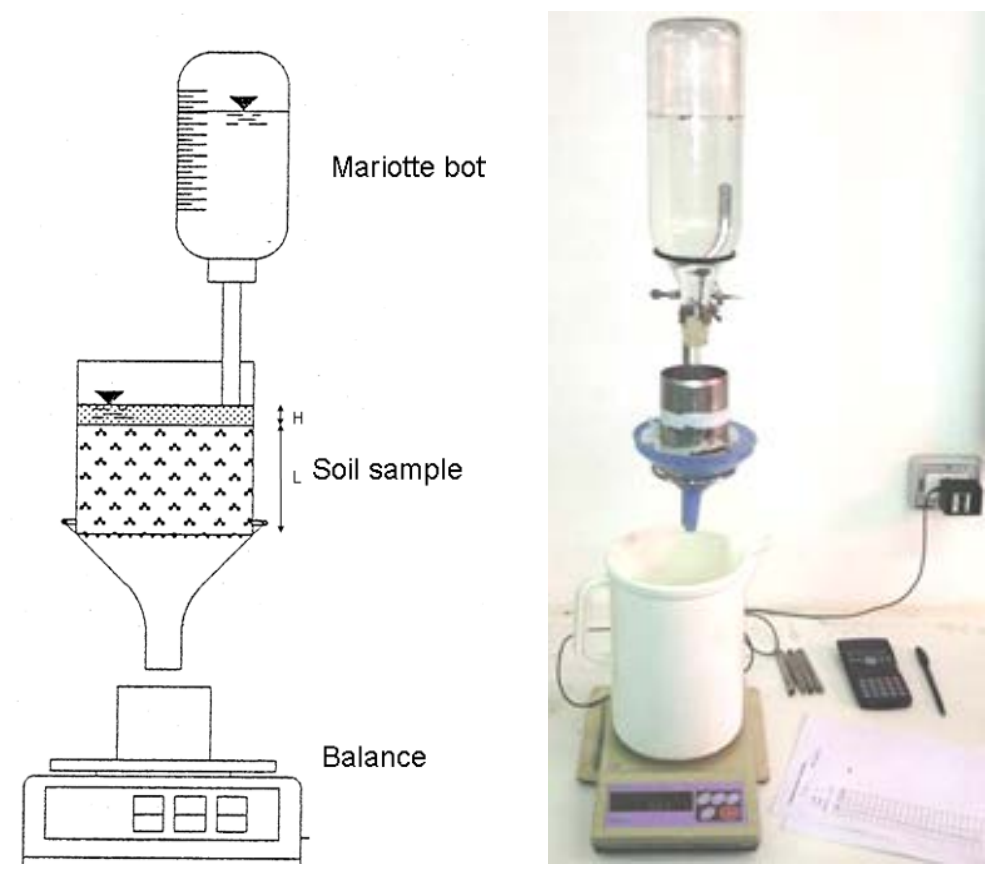

Figure 4. (a) Determination of soil water retention curve with tensiometric, and (b) pressiometric methods.

\section{calibration}

AquaCrop: Model inputs and allowing reproducing mechanisms governing the soil plant atmosphere continuum. A climate station located in the experimental site allowing retrieve agroclimatic data, used as inputs for the weather file. The station provided hourly records of solar radiation, precipitation, maximum and minimum temperature and relative humidity. From these records, reference evapotranspiration (ETo) was computed using the PenmanMonteith Equation. Atmospheric CO concentration, also necessary for the weather file was set according to the default values of AquaCrop. 
Measurements in terms of soil physical characteristics such as saturated volumetric water content, water content at field capacity and at permanent wilting point, saturated hydraulic conductivity were considered to parameterize the soil file. Groundwater table was greatly deeper than the effective root zone.
Since, the action of capillary rise was neglected in the simulation. Initial water contents required for the initial conditions file were determined according to the first measurement. Irrigation files included irrigation depths and its time of application as presented on Table 1.

Table 1. Water amount [mm] provided during each irrigation event in 2014 and 2015.

\begin{tabular}{|c|c|c|c|c|c|c|}
\hline \multirow{9}{*}{ 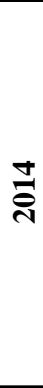 } & Date & T1 & $\mathbf{T} 2$ & Date & T3 & T4 \\
\hline & $29 / 1 / 2014$ & 9.4 & 4.8 & $28 / 1 / 2014$ & 15.5 & 9.2 \\
\hline & $20 / 2 / 2014$ & 11.5 & 6.4 & $19 / 2 / 2014$ & 9.9 & 5.4 \\
\hline & 7/4/2014 & 12.9 & 5.1 & 8/4/2014 & 13.6 & 7.3 \\
\hline & $14 / 4 / 2014$ & 28.2 & 7.1 & $11 / 4 / 2014$ & 27.9 & 17.6 \\
\hline & $17 / 4 / 2014$ & 14.5 & 8.5 & $18 / 4 / 2014$ & 18.8 & 12.6 \\
\hline & $21 / 4 / 2014$ & 5.6 & 8.3 & $24 / 4 / 2014$ & 15.2 & 9.9 \\
\hline & $25 / 4 / 2014$ & 30.1 & 14.7 & $30 / 4 / 2014$ & 11.3 & 5.1 \\
\hline & $30 / 4 / 2014$ & 12.2 & 6.3 & & & \\
\hline & Total & 124.4 & 61.1 & Total & 112.20 & 67.10 \\
\hline \multirow{16}{*}{ 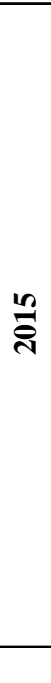 } & Date & T1 & $\mathbf{T} 2$ & Date & T3 & T4 \\
\hline & 27/1/2015 & 11.8 & 6.6 & 27/1/2015 & 7.8 & 4.1 \\
\hline & 5/2/2015 & 11.8 & 6.8 & 5/2/2015 & 12.6 & 8.1 \\
\hline & $12 / 2 / 2015$ & 7.2 & 3.6 & $12 / 2 / 2015$ & 7.3 & 5.3 \\
\hline & 19/3/2015 & 11.4 & 6.5 & 19/3/2015 & 8.1 & 5.3 \\
\hline & 4/4/2015 & 10.5 & 5.3 & 4/4/2015 & 9.1 & 4.7 \\
\hline & $10 / 4 / 2015$ & 16.4 & 8.4 & $10 / 4 / 2015$ & 22.7 & 7.0 \\
\hline & $21 / 4 / 2015$ & 12.1 & 6.2 & $21 / 4 / 2015$ & 10.5 & 5.2 \\
\hline & $24 / 4 / 2015$ & 13.3 & 6.8 & $24 / 4 / 2015$ & 11.6 & 5.7 \\
\hline & 29/4/2015 & 15.3 & 7.7 & 29/4/2015 & 13.2 & 6.6 \\
\hline & 1/5/2015 & 18.2 & 9.3 & 1/5/2015 & 15.8 & 7.9 \\
\hline & 4/5/2015 & 14.0 & 7.1 & 4/5/2015 & 12.1 & 6.0 \\
\hline & 8/5/2015 & 15.5 & 7.9 & 8/5/2015 & 13.5 & 6.7 \\
\hline & $12 / 5 / 2015$ & 8.9 & 4.5 & $12 / 5 / 2015$ & 7.8 & 3.9 \\
\hline & $15 / 5 / 2015$ & 15.4 & 7.7 & $15 / 5 / 2015$ & 13.3 & 6.6 \\
\hline & Total & 181.8 & 94.4 & Total & 165.10 & 83.10 \\
\hline
\end{tabular}

Crop component consisted on a set of calibrated, measured or conservative parameters, mainly articulated on crop parameters of phonology, development and water stress. The only parameters of crop growth that were calibrated using field measurement are maximum canopy cover, the time to reach the maximum canopy cover, maximum root depths and the time to reach maximum root depths. Table 2 bellow contains details about the values of the different parameters used for model calibration. The sources of the parameter (literature, measured, conservative) are also indicated. 
Table 2. Model input parameters and its sources.

\begin{tabular}{|c|c|c|}
\hline Variable & Value & Sources \\
\hline \multicolumn{3}{|l|}{ Crop phenology } \\
\hline Time to emergence, GDD ${ }^{\mathrm{NC}}$ & 322 & M \\
\hline Time to maximum rooting depth, GDD ${ }^{\mathrm{NC}}$ & 956 & $\mathrm{M}$ \\
\hline Time to start tuber formation, GDD ${ }^{N C}$ & 553 & M \\
\hline Time to harvest, GDDNC & 2324 & $\mathrm{M}$ \\
\hline Time to maximum canopy cover $\mathrm{GDD}^{\mathrm{C}}$ & 967 & M \\
\hline Time to tuber formation $\mathrm{GDD}^{\mathrm{C}}$ & 1748 & M \\
\hline \multicolumn{3}{|l|}{ Crop growth and development } \\
\hline Plant density plants $\mathrm{m}^{-2 \mathrm{NC}}$ & 5.8 & M \\
\hline Depth of sowing $\mathrm{m}^{\mathrm{NC}}$ & 0.20 & M \\
\hline Maximum effective root depth $\mathrm{m}^{\mathrm{NC}}$ & 0.25 & M \\
\hline Initial canopy cover, $\%^{\mathrm{C}}$ & 26 & $\mathrm{~L}$ \\
\hline Base temperature, ${ }^{\circ} \mathrm{C}$ & 10 & $\mathrm{~L}$ \\
\hline Upper temperature, ${ }^{\circ} \mathrm{C}$ & 1.1 & $\mathrm{~L}$ \\
\hline Water productivity, $\mathrm{gm}^{-2 \mathrm{C}}$ & 0.65 & $\mathrm{~L}$ \\
\hline Maximum root extraction, mm.day-1C & 0.6 & $\mathrm{~L}$ \\
\hline Crop transpiration coefficient ${ }^{C}$ & 1.15 & $\mathrm{~L}$ \\
\hline Canopy shelter \% ${ }^{\mathrm{C}}$ & 60 & $\mathrm{~L}$ \\
\hline Harvest index\%c & 82 & $\mathrm{~L}$ \\
\hline Water stress & 55.7 & \\
\hline Upper threshold for canopy expansion ${ }^{\mathrm{C}}$ & 0.6 & $\mathrm{~L}$ \\
\hline Lower threshold for canopy expansion ${ }^{C}$ & 0.2 & $\mathrm{~L}$ \\
\hline Upper threshold for stomata closure ${ }^{\mathrm{C}}$ & 0.55 & $\mathrm{~L}$ \\
\hline Shape factor for stomata closure $\mathrm{e}^{\mathrm{C}}$ & 3 & $\mathrm{~L}$ \\
\hline Upper threshold for canopy senescence ${ }^{C}$ & 0.66 & $\mathrm{~L}$ \\
\hline
\end{tabular}

m: measured; l: literature; C: conservative; NC: non-conservative.

The performance of AquaCrop model was evaluated by considering the Mean Bias Error (MBE), the Root Mean
Square Error (RMSE), and the NashSutcliffe model efficiency index (E) (Nash and Sutcliffe, 1970), evaluated as:

$$
\begin{aligned}
& M B E=\frac{1}{N} \sum_{0}^{N}\left(X_{\text {sim }}-X_{o b s}\right) \\
& R M S E=\sqrt{\frac{1}{N} \sum_{0}^{N}\left(X_{\text {sim }}-X_{o b s}\right)} \\
& R M S E=1-\frac{\sum_{0}^{N}\left(X_{s i m}-X_{o b s}\right)^{2}}{\left(X_{s i m}-\overline{X_{o b s}}\right)^{2}}
\end{aligned}
$$

where $X_{\text {sim,i }}$ and $X_{\text {obs,iare }}$ the simulated and observed values of any considered variable at the time $\mathrm{i}$ and $\mathrm{N}$ the number of measured data. 


\section{Results}

Figure 5 shows temporal trends of $\mathrm{ET}_{0}$, and precipitation, $\mathrm{P}$, during the growth season 2014 and 2015. As can be observed, there a first period on which
ET0 varied around a average value of $1 \mathrm{~mm} /$ day to increase linearly till the end of the season. However, this increase occurred earlier in 2015. Since, ET0 reached higher values in 2015 compared to 2014 .
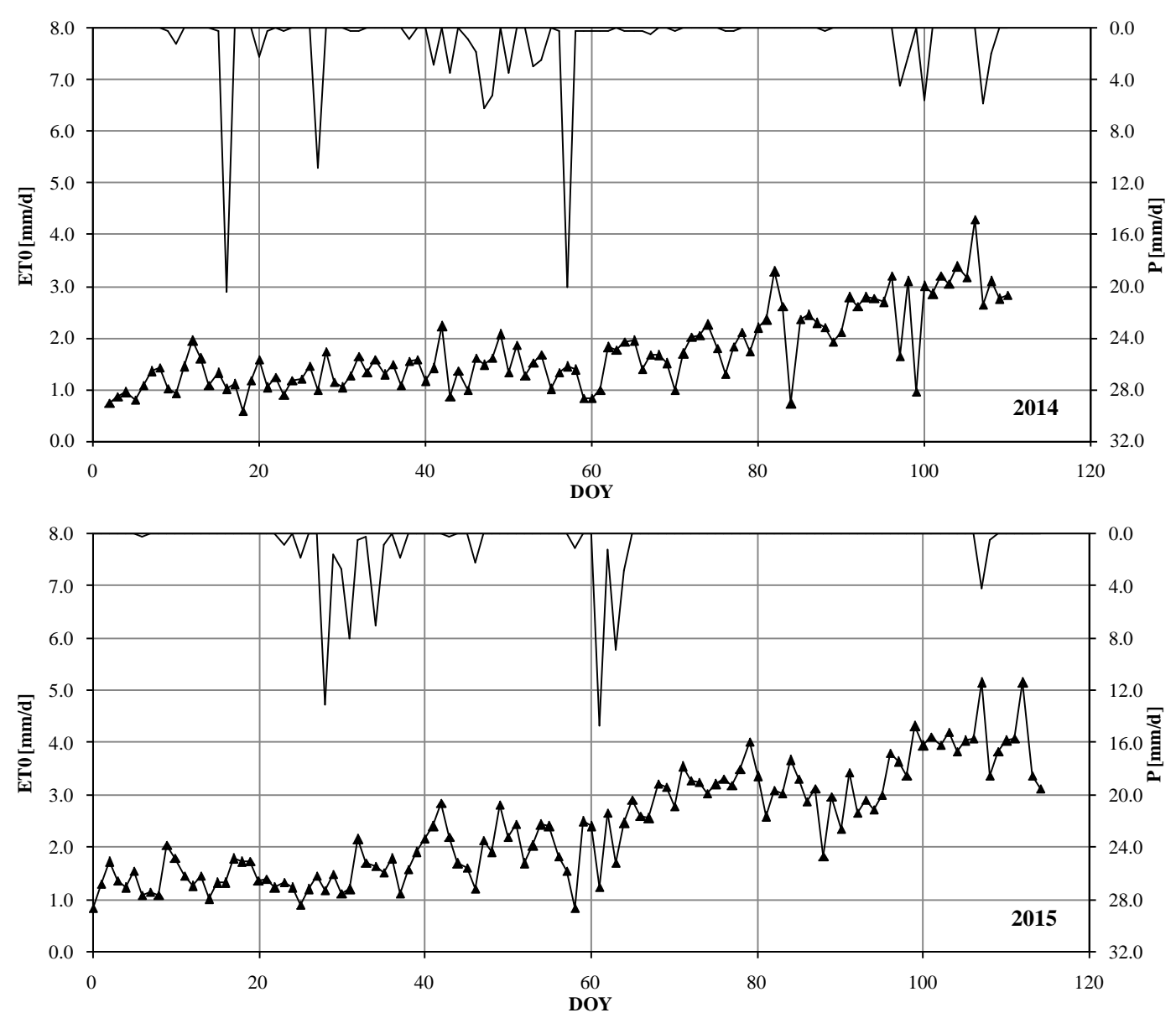

Figure 5. Temporal trends of ET0, and precipitation (P) during the growth season 2014 and 2015.

Figure 6 shows the particle size distribution curves for three layers $00-20$ $\mathrm{cm}, 20-40 \mathrm{~cm}$, and $40-60 \mathrm{~cm}$ ) of the experimental soil profile. The percentages of clay, silt and sand were evaluated based on the USDA (United States Department of Agriculture) particle size classification system. Soil texture resulted rather similar in the three examined layers, with clay content ranging between $17.3 \%$ and $17.9 \%$, silt content between $14.3 \%$ and $15.9 \%$ and sand content between $66.9 \%$ and $68.1 \%$, indicating certain homogeneity of soil mineral particles along the profile. 


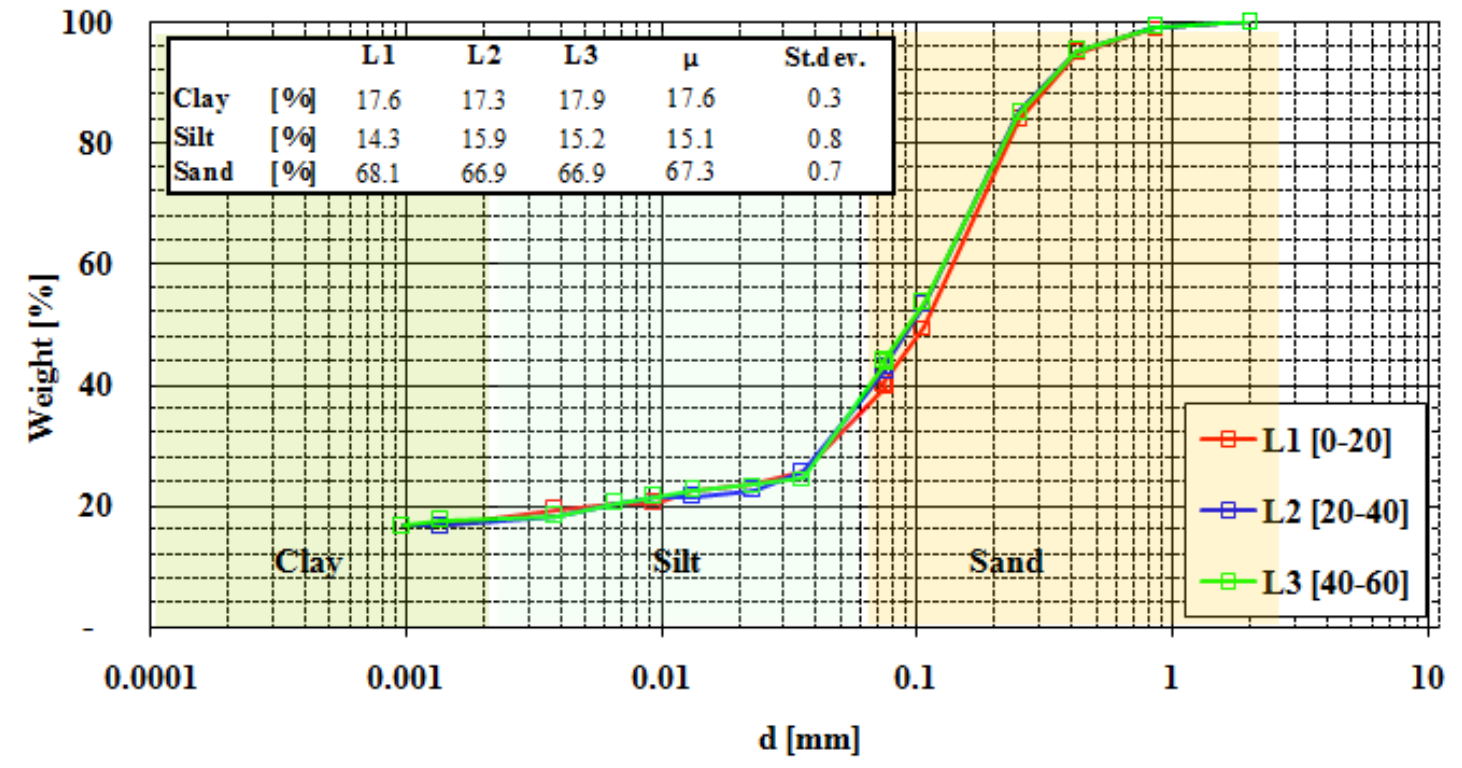

Figure 6. Particle size distribution curves for three layers of the investigated soil profile.

When considering the fractions of each soil separate (sand, silt, and clay) present in the three layers, according to the soil textural triangle shown in Figure 7, it can be noticed that all three samples fall into the same textural class of sandy loam soils. The average bulk density and saturated hydraulic conductivity, $\mathrm{K}_{\mathrm{s}}$, the three examined layers, whose values are indicated in Table 3, were determined on the same undisturbed cylindrical samples $(8.0 \mathrm{~cm}$ diameter and $5.0 \mathrm{~cm}$ height) later used to determine the water retention curve.

Table 3 shows that the upper soil layer $(0-20 \mathrm{~cm})$ is characterized by the lowest bulk density and the highest saturated hydraulic conductivity, as consequence of plowing that usually involves this layer. Moreover, at rising depth the values of soil bulk density increase, whereas saturated hydraulic conductivities decrease, as result of soil compaction.

The values of matric potential, $h$, versus the volumetric soil water content in the layers $0-20 \mathrm{~cm}, 20-40 \mathrm{~cm}$, and $40-$ $60 \mathrm{~cm}$, determined with the hanging water column apparatus for $h$ values ranging from saturation to $-150 \mathrm{hPa}$ and with pressure plate apparatus (Dane and Hopmans, 2002) for the lower matric potentials, are shown in Figure 8a,c. Experimental data were fitted in accordance with Van Genuchten Model (Van Genuchten, 1980) by using the nonlinear fitting software SWRC-Fit (Seki et al., 2007). The limited differences between soil water contents measured at the different layers for each fixed matric potential, allowed to consider an averaged soil water retention curve for the entire soil profile (Figure 8). 


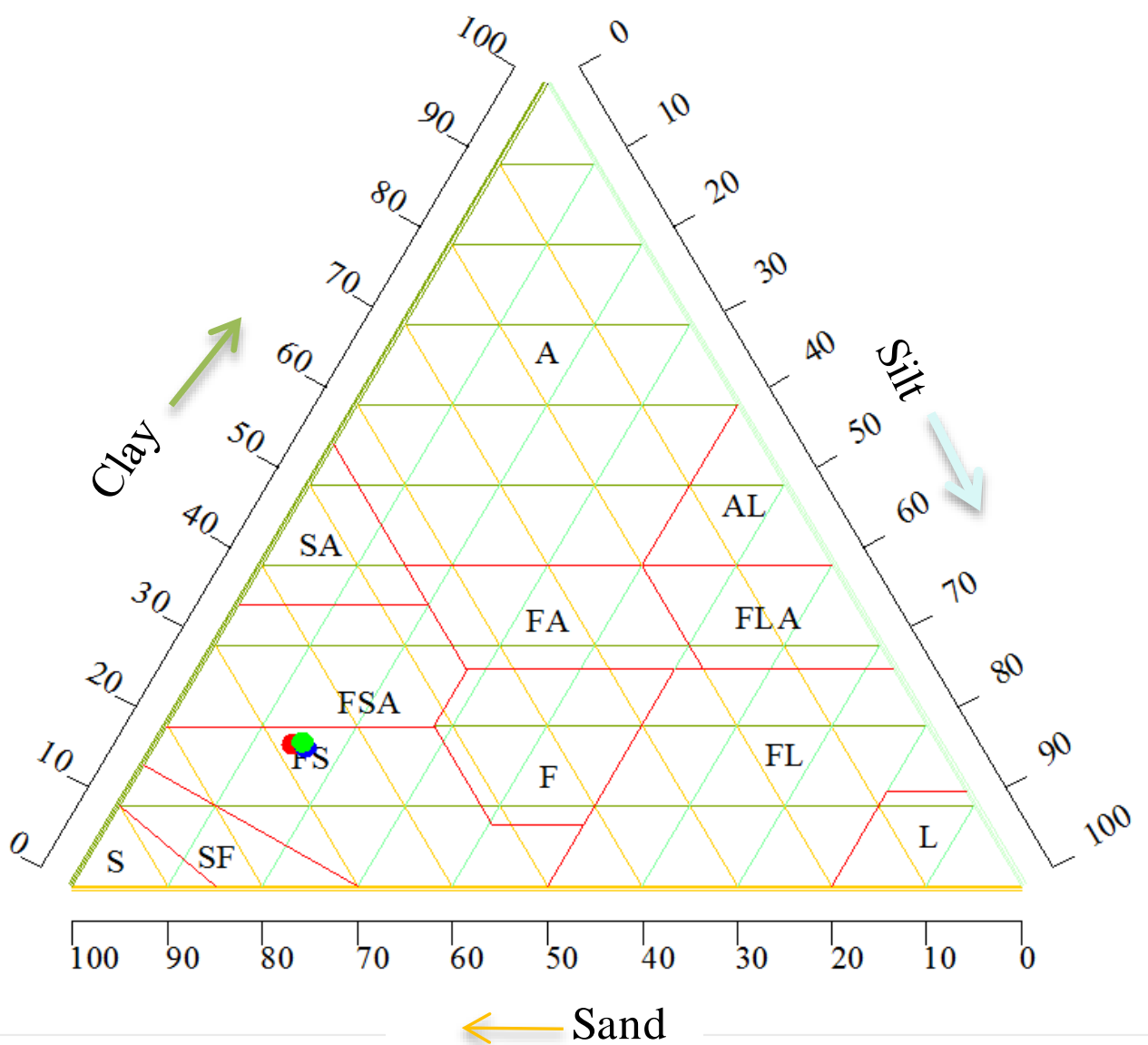

Figure 7. Soil classification of the three soil layers according to USDA textural triangle.

Table 3. Soil bulk density and saturated hydraulic conductivity (Ks) for the investigated soil layers.

\begin{tabular}{lccc}
\hline Sample & Depth $[\mathbf{c m}]$ & Bulk density $[-]$ & $\mathbf{K}_{\mathbf{s}}\left[\mathbf{c m ~ \mathbf { ~ h } ^ { - 1 } ]}\right.$ \\
\hline L1 & $0-20$ & 1.27 & 11.0 \\
L2 & $20-40$ & 1.43 & 6.4 \\
L3 & $40-60$ & 1.47 & 3.8 \\
\hline
\end{tabular}



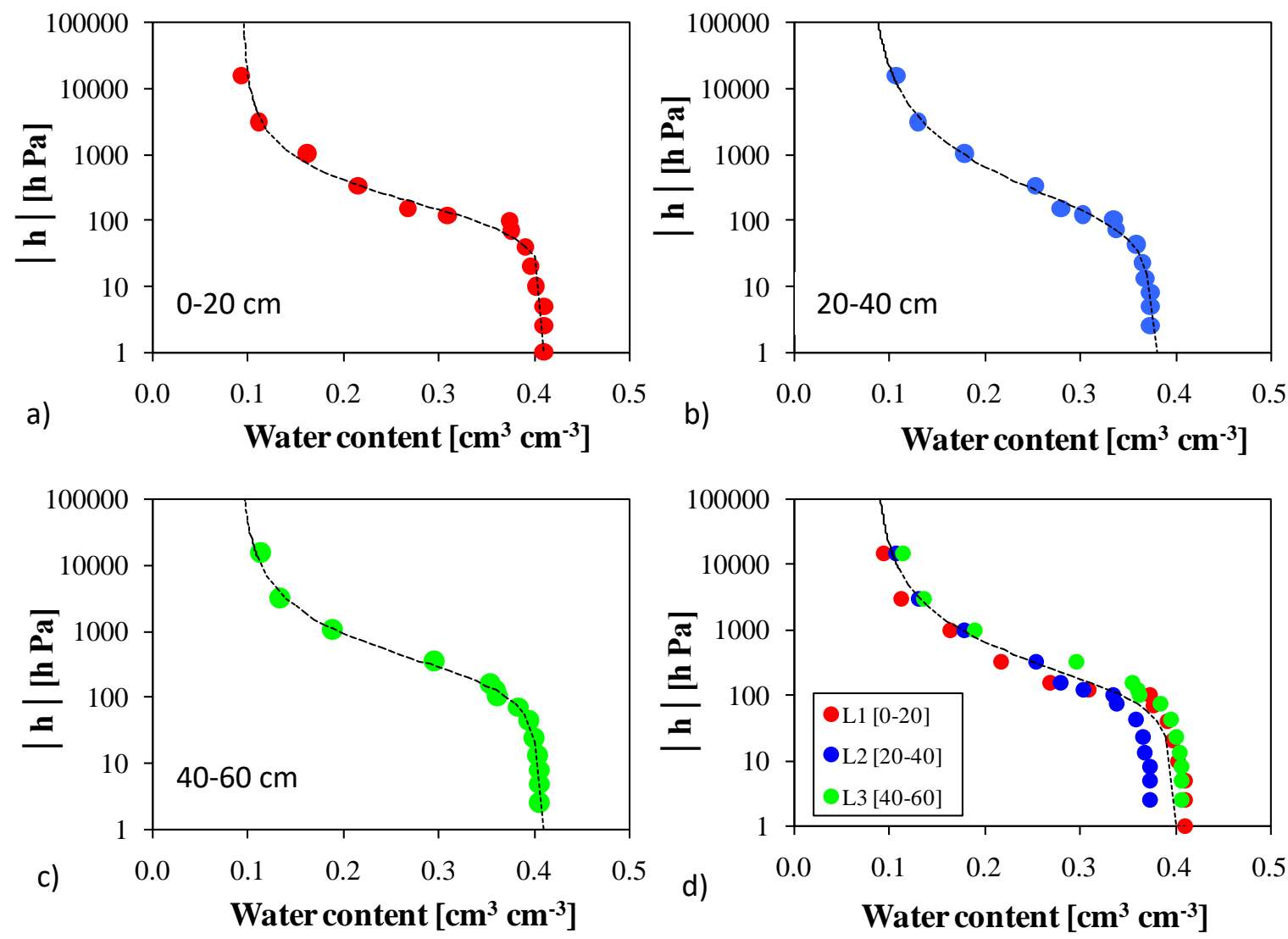

Figure 8. Experimental values of matric potential versus soil water content for the three investigated soil layers. SWRCs in accordance with Van Genuchten Model are also represented. The average curve for all the layers is shown in the lower right box (d).

Table 4. Indicates the Van Genuchten parameters of water retention curves for the three investigated soil layers (L1, L2 and L3) and for the whole soil profile (all data). For each fitted curve, the coefficient of determination, R2, is also indicated.

\begin{tabular}{l|ll|ll|ll|ll}
\hline & \multicolumn{2}{|c|}{ L1 [0-20 cm] } & \multicolumn{2}{c|}{ L2 [20-40 cm] } & \multicolumn{2}{c|}{ L3 [40-60 cm] } & \multicolumn{2}{c}{ All Data } \\
\hline Model & Parameters & $\boldsymbol{R}^{\mathbf{2}}$ & Parameters & $\boldsymbol{R}^{\mathbf{2}}$ & Parameters & $\boldsymbol{R}^{\mathbf{2}}$ & Parameters & $\boldsymbol{R}^{\mathbf{2}}$ \\
\hline \multirow{3}{*}{ Van } & $\theta_{\mathrm{s}}=0.41$ & & $\theta_{\mathrm{s}}=0.37$ & & $\theta_{\mathrm{s}}=0.40$ & & $\theta_{\mathrm{s}}=0.39$ & \\
Genuchten & $\theta_{f c}=0.29$ & & $\theta_{f c}=0.26$ & & $\theta_{f c}=0.28$ & & $\theta_{f c}=0.27$ & \\
$(1980)$ & $\theta_{\mathrm{r}}=0.08$ & 0.98 & $\theta_{\mathrm{r}}=0.07$ & 0.99 & $\theta_{\mathrm{r}}=0.08$ & 1.0 & $\theta_{\mathrm{r}}=0.08$ & 0.96 \\
& $\alpha=0.01$ & & $\alpha=0.01$ & & $\alpha=0.01$ & & $\alpha=0.01$ & \\
& $\mathrm{n}=1.83$ & & $\mathrm{n}=1.49$ & & $\mathrm{n}=1.69$ & & $\mathrm{n}=1.59$ & \\
\hline
\end{tabular}

Table 4 indicates the van Genuchten parameters of water retention curves for the three investigated soil layers (L1, L2 and L3) and for the whole soil profile (all data). For each fitted curve, the coefficient of determination, $\mathrm{R}^{2}$, is also indicated.
Once estimated the SWRC parameters, soil water contents at field capacity, $\theta_{f c}$, and at wilting point, $\theta_{w p}$, were evaluated on the basis of soil matric potential equal to $-330 \mathrm{hPa}$ and $-15,000$ hPa. 
T1

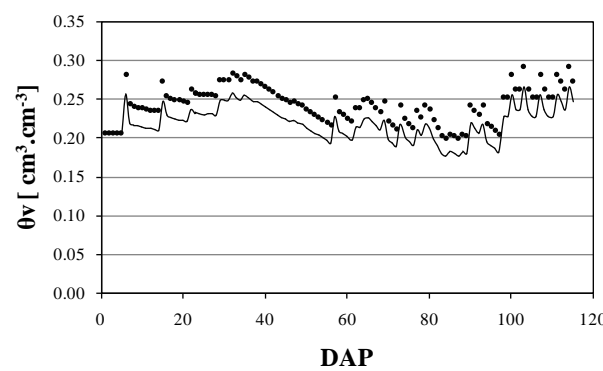

\section{$(20 \mathrm{~cm})$}

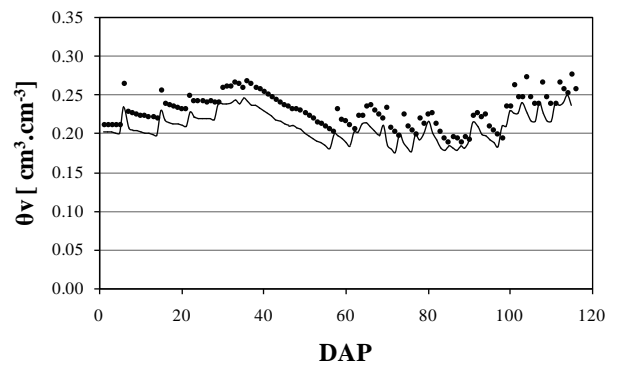

\section{$(30 \mathrm{~cm})$}

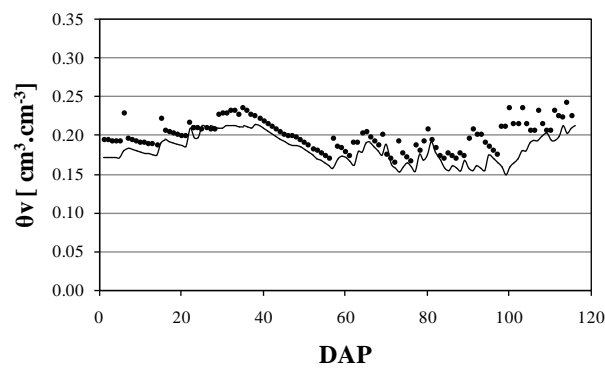

$(40 \mathrm{~cm})$

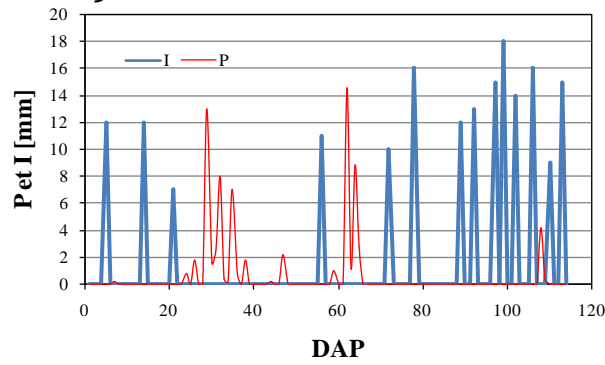

T2

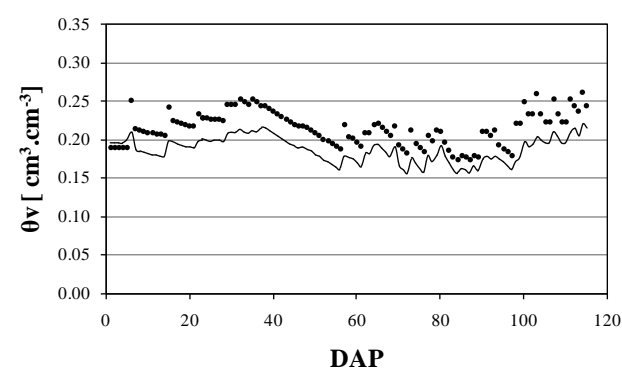

$(20 \mathrm{~cm})$

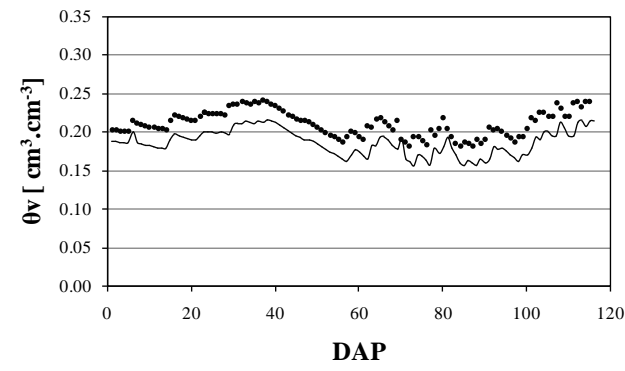

$(30 \mathrm{~cm})$

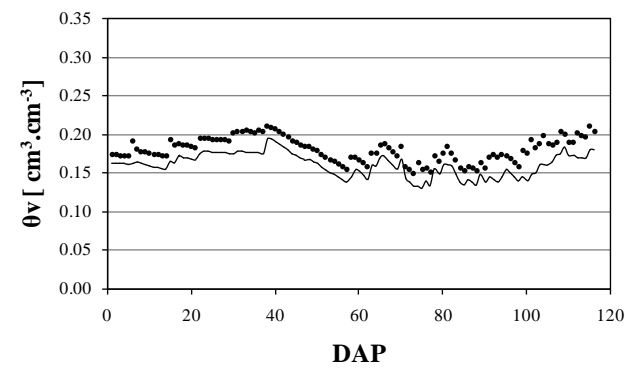

$(40 \mathrm{~cm})$

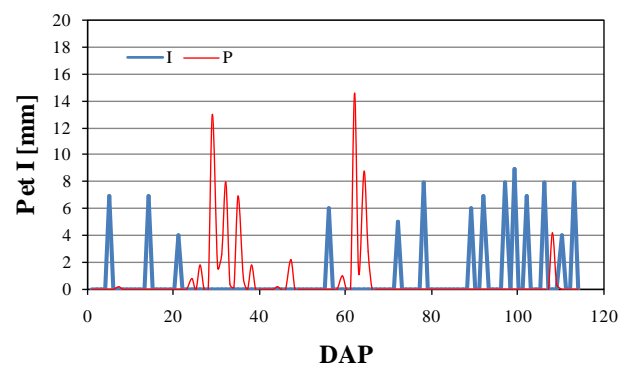

Figure 9. Comparison between measured (black dots) and simulated (solid line) SWCs, $\theta \mathrm{v}$, in treatment T1 and T2 (2015) at depths 10, 20, 30 and $40 \mathrm{~cm}$ from the emitter. are shown in the right column. Irrigation and precipitation events are also shown.

AquaCrop simulation for water content prediction

Before using AquaCrop for simulating water contents, the model was calibrated under soil and climate conditions. Results of laboratory analysis were used to parameterize the soil profile. Values presented on Table 3 and Table 4 were used for crop calibration. Irrigations were introduced following the 
scheduling practiced on the field. Thereafter, the model was run to simulate water contents under the experimental compaign of 2015, because measurements were more intensive. Figure 9 shows a comparison between simulated and measured soil water contents for $\mathrm{T} 1$ and $\mathrm{T} 2$ for the investigated year.

Table 5 summarizes the number of measured values, $\mathrm{N}$, the statistical values of the mean square error, MBE, the square root of the error, RMSE and the Nash-Sutcliffe Coefficient, E, obtained on the basis of the observed and measured values of water contents. Values of MBE, were always negative, confirming that model underestimated soil water contents. As shown on the table, the RMSE values were always lower than $0.04 \mathrm{~cm}^{3} . \mathrm{cm}^{-3}$, suggesting that simulated $\theta \mathrm{v}$ fitted to the measured $\theta \mathrm{v}$ in the $40 \mathrm{~cm}$ soil layer. This result was also confirmed with the Nash coefficient (Moriasi et al., 2007).

Table 5. Statistical indicators for water content prediction for the calibration dataset.

\begin{tabular}{lcc}
\hline & T1 & T2 \\
\hline N & 347 & 347 \\
MBE & -0.02 & -0.03 \\
RMSE & 0.02 & 0.03 \\
E & 0.71 & 0.62 \\
\hline
\end{tabular}

Once testing the model under the soil and climatic condition of 2015 , the performance of well simulating water contents was examined for the experimental compaign of 2014. Figure 10 shows a comparison between estimated and measured water contents for T1 and T2 treatments. Analysis of these figures confirms the previous results of the ability of the model to simulate average water contents.
$\mathrm{T} 1$

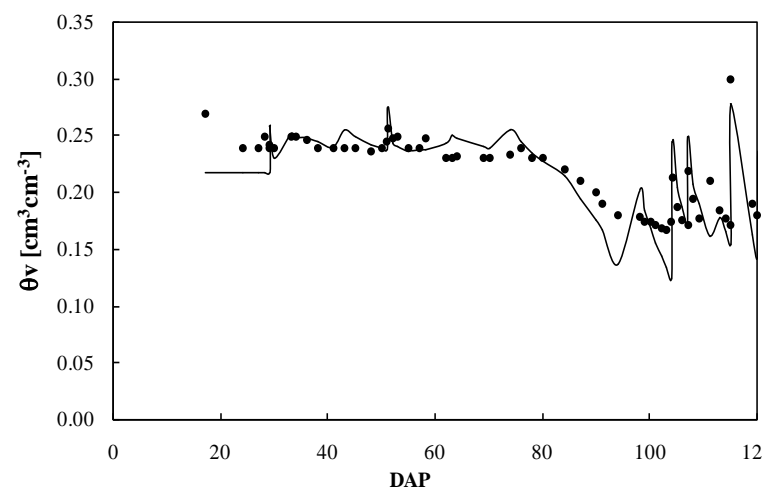

$\mathrm{T} 2$

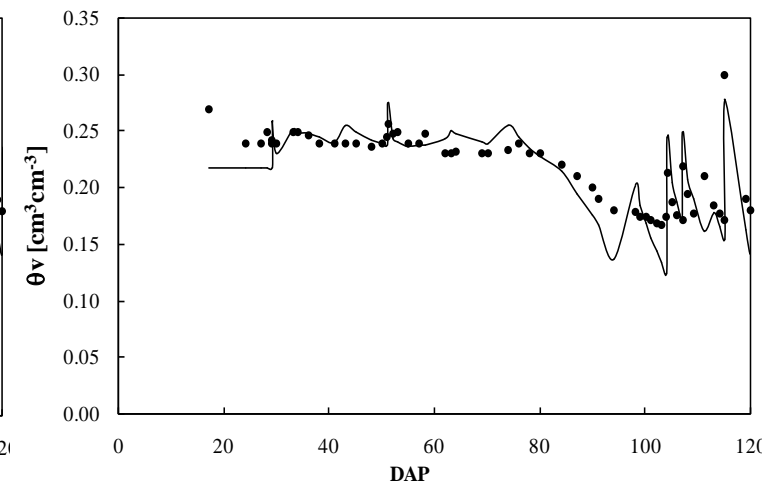

Figure 10. Comparison between average measured (black dots) and simulated (solid line) SWCs, $\theta \mathrm{v}$, in treatment T1 and T2 (2014). 


\section{Discussion}

Following the preliminarily calibration above described, it was confirmed that AquaCrop model is able to reproduce the dynamics of measured values of water content, with some underestimation. Furthermore, AquaCrop reproduced the local peaks corresponding to the irrigation and rainfall events. However, the horizontal spatial variability that is not assumed on AquaCrop could justify the observed mismatch between simulated and measured values. Moreover, measurements were punctual and AquaCrop allowed simulating water contents over a complete horizon. However, it was evident that the difference between simulated and measured values increased in superficial layers. This result could be returned to the exact depth of drip line that AquaCrop does not allow to set. Similarly, the difference was generally accentuated towards the end of the season, which is probably justified by the presence of tubers that could disturb the measurements. When comparing $\mathrm{T} 1$ and T2 treatments, it is confirmed that the better vegetation cover and production, observed in $\mathrm{T} 1$, were mainly related to greater water availability, especially because maximum rooting depth did.

In 2014, the potato crop was planted on the same field of 2015 and was used as a control test for evaluating the calibration of the AquaCrop software. During this year, AquaCrop was unable to reproduce the punctual dynamic of soil water content. However, simulated average values were considered acceptable. The presence of grape of air between soil and measurement tube, observed especially during that season, could justify this inability. Moreover, for both years, statistical parameters showed lower performance under deficit irrigation. These results are in agreement with those reported ones by Farhani et al. (2009) and Peredes et al. (2014) who found discrepancies between simulated and measured soil water contents were higher under lower watering volumes. However, Raes et al. (2012) found that better is the parameterization of plant growth in terms of canopy cover, better will be the performance of the model in simulating soil water contents.

\section{Conclusion}

In this study, AquaCrop was calibrated to estimate water contents for two irrigations strategies under the semiarid condition of Tunisia. During the calibration procedure, several iterations were investigated to test the possibility to use the conservative parameters proposed by AquaCrop, under the semiarid condition of the Tunisia. Results showed that the model was able to simulate water contents $(\theta v)$. Statistical indicators for root mean square error (RMSE), Mean Bias Error (MBE), Nasch coefficient $(E)$ and coefficient of determination $\left(\mathrm{R}^{2}\right)$ for $\mathrm{CC}$ and $\mathrm{Y}$ underlined that model performance was better under non stressed plots. In general, values of RMSE were lower than $0.03 \mathrm{~cm}^{3} . \mathrm{cm}^{-3}$ and values of $\mathrm{E}$ were close to 1 confirming the goodness of fit between measured and estimated water contents. Once assessed, this model could be used to study effects of different irrigation strategies on dynamic of water contents aiming to increase water use efficiency. However, further investigations should be carried out to ameliorate the parameterization of crop vegetative growth.

\section{Conflict of interest}

The authors declare that there is no conflict of interest.

\section{References}

Allen, R. G.; Pereira, L. S.; Raes, D.; Smith, M. Crop evapotranspiration: Guidelines for computing crop water requirements. Rome: Food, 1998. (FAO Irrigation and Drainage, Paper 56). 
Bagnouls, F.; Gaussen H. Saison sèche et indice xérothermique. Documents pour les Cartes des Productions Vegetales, Tome III(1), Toulouse, 1953.

Dane, J. H.; Hopmans, J. W. Pressure plate extractor. In: Dane, J. H.; Topp, G. C. (Eds.). Methods of soil analysis. Part 4. Physical methods. Madison, WI: SSSA, 2002. (SSSA Book Serie, 5). p. 688-690.

Dane, J. H.; Topp, G. C. Methods of soil analysis. Part 4: Physical methods. Madison: Soil Science Society of America, 2002. (SSSA Book Serie, 5).

Farahani, H. J.; Izzi, G.; Oweis, T. Y. Parameterization and evaluation of the AquaCrop model for full and deficit irrigated cotton. Agronomy Journal, v. 101, no. 3, p. 469-476, 2009. https://doi.org/10.2134/ agronj2008.0182s

Heng, L. K.; Hsiao, T.; Evett, S.; Howell, T.; Steduto, P. Validating the FAO AquaCrop model for irrigated and water deficient field maize. Agronomy Journal, v. 101, no. 3, p. 488-498, 2009. https://doi.org/10.2134/ agronj2008.0029xs

Hsiao, T. C.; Heng, L.; Steduto, P.; Rojas-Lara, B.; Raes, D.; Fereres, E. AquaCrop: The FAO crop model to simulate yield response to water: III. Parameterization and testing for maize. Agronomy Journal, v. 101, no. 3, p. 448-459, 2009. https://doi.org/10.2134/ agronj2008.0218s

Jury, W. A.; Vaux, H. The role of science in solving the world's emerging water problems. PNAS, v. 102 , no. 44 , p. $15715-$ 1572, 2005. https://doi.org/10.1073/ pnas. 0506467102

Katerji, N.; Campi, P.; Mastrorilli, M. Productivity, evapotranspiration, and water use efficiency of corn and tomato crops simulated by AquaCrop under contrasting water stress conditions in the Mediterranean Region. Agricultural Water Management, v. 130 , p.14-26, 2013. https://doi.org/ 10.1016/j.agwat.2013.08.005

Kawakami, J.; Iwama, K.; Jitsuyama, Y. Effects of planting date on the growth and yield of two potato cultivars grown from microtubersand conventional seed tubers. Plant Production Science, v. 8, no. 1, p. 7478, 2005. https://doi.org/10.1626/pps.8.74
Moriasi, D. N.; Arnold, J. G.; Van Liew, M. W.; Bingner, R. L.; Harmel, R. D.; Veith T. L. Model evaluation guidelines for systematic quantification of accuracy in watershed simulations. Transaction of the American Society of Agricultural and Biological Engineers, v. 50, no. 3, p. 885-900, 2007. https://doi.org/10.13031/2013.23153

Nash, J. E.; Sutcliffe, J. V. River flow forecasting through conceptual model. Part 1: A discussion of principles. Journal of Hydrology, v. 10, no. 3, p. 282-290, 1970. https://doi.org/10.1016/0022-1694(70)90 255-6

Paredes, P.; Rodrigues, G. C.; Alves, I.; Pereira, L.S. Partitioning evapotranspiration, yield prediction and economic returns of maize under various irrigation management strategies. Agricultural Water Management, $\quad$ v. 135, p. 27-39, 2014. https://doi.org/10.1016/j.agwat.2013.12.010

Raes, D.; Steduto, P.; Hsiao, T. C.; Fereres, E. AquaCrop Reference Manual: Version 4. Rome, Italy: FAO Land and Water Division, 2012.

Rallo, G.; Agnese, C.; Minacapilli, M.; Provenzano, G. Comparison of SWAP and FAO agro-hydrological models to schedule irrigation of wine grape. Journal of Irrigation and Drainage Engineering, v. 138, no. 7, p. 581-591, 2012. https://doi.org/10.1061/(ASCE)IR.19434774.0000435

Seki, K. SWRC fit: A nonlinear fitting program with a water retention curve for soils having unimodal and bimodal pore structure. Hydrology and Earth System Science Discussion, v. 4, p. 407-437, 2007. https://doi.org/10.5194/hessd-4-407-2007

Shahnazari, A.; Liu, F.; Andersen, M. N.; Jacobsen, S.-E.; Jensen, C. R. Effects of partial root-zone drying on yield, tuber size and water use efficiency in potato under field conditions. Field Crops Research, v. 100, no. 1, p.117-124, 2007. https://doi.org/ 10.1016/j.fcr.2006.05.010

Šimůnek, J.; Van Genuchten, M. Th. Modeling nonequilibrium flow and transport with HYDRUS. Vadose Zone Journal, v. 7, no. 2, p. 782-797, 2008. https://doi.org/10.2136/ vzj2007.0074 
Steduto, P.; Hsiao, T.C.; Raes D.; Fereres, E. AquaCrop: The FAO crop model to simulate yield response to water: I. concepts and underlying principles. Agronomy Journal, v. $101, \quad$ no. $3, \quad$ p. $426-437, \quad 2009$. https://doi.org/10.2134/agronj2008.0139s

Van Dam, J. C.; Groenendijk, P.; Hendriks, R. F. A.; Kroes, J. G. Advances of modeling water flow in variably saturated soils with SWAP. Vadose Zone Journal, v. 7, p. 640-653, 2008. https://doi.org/10.1016/j.fcr.2006.05.010 original work is properly cited. 